\title{
Analysis of the Gearbox Oil Maintenance Procedures in Wind Energy II
}

\author{
José Ramón del Álamo Salgado ${ }^{1, *}$, Mario J. Durán Martínez ${ }^{2}$, Francisco J. Muñoz Gutiérrez ${ }^{2} \mathbb{D}$ and Jorge Alarcon ${ }^{3}$ \\ 1 Eolia Renovables, 29010 Málaga, Spain \\ 2 Department of Electrical Engineering, School of Engineering, University of Malaga, 29016 Málaga, Spain; \\ mjduran@uma.es (M.J.D.M.); fjmg@uma.es (F.J.M.G.) \\ 3 Bureau Veritas-Oil Condition Monitoring, Houston, TX 77477, USA; Jorge.alarcon@bureauveritas.com \\ * Correspondence: jrdelalamo@hotmail.com
}

Citation: Salgado, J.R.d.Á.; Martínez, M.J.D.; Gutiérrez, F.J.M.; Alarcon, J. Analysis of the Gearbox Oil Maintenance Procedures in Wind Energy II. Energies 2021, 14, 3572. https://doi.org/10.3390/en14123572

Academic Editor: Alvaro Luna

Received: 7 May 2021

Accepted: 8 June 2021

Published: 16 June 2021

Publisher's Note: MDPI stays neutral with regard to jurisdictional claims in published maps and institutional affiliations.

Copyright: (c) 2021 by the authors. Licensee MDPI, Basel, Switzerland. This article is an open access article distributed under the terms and conditions of the Creative Commons Attribution (CC BY) license (https:/ / creativecommons.org/licenses/by/ $4.0 /)$.

\begin{abstract}
Recent works have addressed the analysis of some situations that alter the gearbox oil results in wind energy conversion systems (WECS). This work contributes by completing the analysis of additional situations, based on key operational data collected from 10 different multi-megawatt wind turbines at two different locations with two top-tier technologies, and has demonstrated that the oil analysis results can be altered in practice. As important as detecting these situations is to verify how the data collected by the different operators and transferred to the laboratories, this relevant information is not included in most cases. The issues that can stem from this lack of valuable data can be mitigated with a new and more complete template. This paper proposes a detailed template that is ready for an industrial use and contributes to standardizing the information handled by all actors. The suggested template, which is designed based on extensive experimental results and an in-depth analysis, provides detailed information for laboratories to improve conclusions, recommendations and action plans. The investigation provides a high archival value for researchers whose investigation deals with gearbox oil maintenance. Furthermore, the global impact of the proposal on the wind industry can be very relevant in terms of benefits and it will ultimately be an advance in the evolution of the operation and maintenance of wind farms.
\end{abstract}

Keywords: scheduled maintenance; predictive maintenance; wind energy; wind turbine gearbox; oil analysis; prognosis

\section{Introduction}

Along with the steady increase of the installed power and the development of new multi-MW wind energy systems, the improvements in term of reliability have been a key feature for the success of this renewable energy [1]. In this context, in the wind energy industry predictive maintenance has its main impact in the areas of productivity and competitiveness [2]. Most wind turbines are equipped with a gearbox, that contributes with well-known benefits, but also adds a new potential source of eventual failure. Thereby, it becomes of paramount importance to establish a clear and effective maintenance procedure to minimize unscheduled shutdowns of the wind turbine [3].

Specifically, the correct diagnosis of the oil gearbox is nowadays even more relevant in order to extend the useful life of the oil. The usual practice years ago was to simply change the oil periodically. This period, which depended on the maintainer and the type of oil, ranged regularly from two to five years. In recent years, these routines have been modified and the oil is now used until the results of the analytics reveal an important degradation or the oil is discarded for another reason, such as gearbox replacement.

The analysis of the oil in the laboratories is executed in an extremely neat and clean environment, hence the probability of contamination once the sample is in this atmosphere is minimal. However, the situation at the beginning of the process, that is, at the wind turbine, or even substations or warehouses, is different. It is at this stage when the risk 
of oil sample contamination is higher. It is determinant that impurities do not enter the sample bottle before, during or after an oil sample is taken. If any impurities are present in the sample, it will alter the results, which in some cases will be detected as erroneous and rejected, but in other cases will be accepted as a "false positive". This process must be very scrupulous and, for this reason, some implemented protocols include actions such as: (i) the bottle must only be opened at the exact moment of the sample being taken for the minimum period of time that is strictly necessary, (ii) the surrounding area of the sample valve must be as clean as possible, (iii) the amount of oil equal to a particular volume indicated by maintainers and laboratories must be discarded, or (iv) the oil samples should be sent to laboratories after the sample is collected within a certain period of time stipulated by maintainers and laboratories.

In recent years, an improvement in the properties and reliability of the oil has extended degradation times and has contributed to a better adaptation to the specific conditions of wind turbine gearboxes [4]. Additionally, the advances in laboratories bring better and more reliable results. Even the knowledge of the oil analytics of gearboxes and the common errors have been refined. Much of the relevant information comes directly from the companies or laboratories involved in this sector rather than from scientific and specialized publications, therefore an important current state of art of some of the most important companies in the industry has been analysed in Section 2 [1].

Nevertheless, the communication between the wind farm (sampling) and the laboratory still has deficiencies with important implications. In the analysis of the gearbox oil parameters not only the trends are important, but also the relationship between those parameters. This "gap" in communication affects the interpretation of the results and their conclusions, triggering generic or simply wrong conclusions that can have severe consequences. This lack of information of relevant events transmitted to the laboratory sometimes implicates generic recommendations that may contain various options, be erroneous or not identify specific severe issues [5].

Despite the fact that the troubleshooting techniques have improved in the wind energy sector in general [6] and for gearboxes in particular [7] (avoiding a relevant percentage of substitution and reducing costs of the handling), the substitution of a gearbox is one the most expensive tasks in the wind energy industry. Therefore, any and all information that can help to make a decision in advance, is crucial and has a significant economic impact [8].

Furthermore, offshore installed power is increasing year after year [9] and the general tendency of the wind turbine sizes is to grow [10]. In offshore wind energy, the atmospheric conditions that may be present, with factors such as high winds and the seawaves [11], complicate the work and the crane cost multiplies compared to onshore wind energy [12], so predictive maintenance is even more important [13].

Recent works [14] have covered general aspects of different issues related to the wind energy industry and its maintenance procedures, including: (i) the significant growth of the wind industry in recent years [1] and the current and future growth trends, (ii) maintenance evolution [2], with the emergence of new tools and spare parts and wider knowledge of assets or (iii) the specific circumstances that hinder the operation and maintenance of a wind farm [15], including the particular features of the wind turbines. More specifically, it is also examined in [14] the gearbox of a wind turbine [16], its maintenance (predictive, preventive and corrective) [2,17] with different techniques that are used to analyse the different issues [18], and the difficulties of collecting and analysing the data $[19,20]$.

Although [14] pointed at some specific problems in the actual maintenance of wind energy system gearboxes, it mainly focused on the identification of failure sources [21,22]. From an analytical perspective, it highlighted how the lack of proper information can significantly alter the system reliability.

Based on the grounds that were set in [14], this work further expands and completes the previous analysis with an in-depth study that includes:

(i) Detailed information about the information that is received by laboratories from different parties in the wind energy industry (Section 2). This data is not present in 
literature, but it is a key issue to confirm that the current information at industry is scarce and incomplete in most cases.

(ii) The specific situations which are part of the daily routines within the operation and maintenance of a wind farm and which can modify the conclusions of the oil analysis results of the gearboxes. At this point the information from [14] is gathered, briefly summarized and completed with the analysis of the air filter substitution (Section 3.1).

(iii) The analysis of the values prior to damage (i.e., the anticipated knowledge of an incident [23]), including previous trends to identify possible behaviour patterns, in order to tackle the problem in its earliest stages (Sections 3.2 and 4). Different case studies are presented and discussed to exemplify how correct information from maintenance staff could eventually lead to prognosis and help the predictive maintenance. By reversing the flow of information, in such a way that operational information supports oil analytics to be part of the information used to make other decisions, generating an integral process.

(iv) The proposal of a sample template that mitigates the lack of information already confirmed in point (i) (Section 2), avoids the erroneous conclusions analysed in (ii) (Section 3) and eventually helps the prognosis with proper information of the parameter trends discussed in (iii) (Section 4). Therefore, the suggested template is the final result of the in-depth analyses detailed in [14] and Sections 3-5 of this paper. It is expected to provide both a high archival value in the scientific community and a practical contribution for practitioners in the field.

The paper is structured as follows: Section 2 analyses the state of art in different companies [24] and laboratories [25], thoroughly examining the information sent from the operator to the laboratory and the type of laboratory conclusions. Section 3 firstly reviews the effect of the substitution of the air filter on the results of the analysis [26], and secondly analyses the importance of the anticipated knowledge of an incident [27]. Section 4 provides experimental results from 10 wind turbines at two different locations with different technologies to analyse and discuss real situations where results can be altered. In Section 5 a proposal for a template to be sent from the wind farm to the laboratory is included with all the relevant information that the laboratory should have to contribute with better conclusions and recommendations for each analytic. Finally, Section 6 details the most relevant conclusions and future outlook.

The new insight and conclusions that have been extracted from this study are expected to provide a high archival value for researchers and practitioners, setting the basis to develop further research on the field and more precise industry actions. This will be not only for maintainers in modifying and adding information to share with the laboratories, but also for laboratories, who, with more information and more detail, will be in a position to offer more specific and accurate conclusions and recommendations.

\section{State of Art of the Information Exchanged between Different Companies and Laboratories}

The content of the information that accompanies each oil sample structure can be defined by two parties: the maintainer and the laboratory. Considering that there are several laboratories [19] and maintainers [18], the consequence is that the information that the laboratories receive is not widely standardized.

Historically the labels that accompany the bottle with the sample had little information, but the situation has been improving in recent years. Nevertheless, there are different situations in the operation of a wind farm that are practically never reflected in the information received by the laboratory.

In Tables 1-7 this information from eight of the main maintainers and laboratories is collected. The different topics are: (i) wind farm, (ii) wind turbine, (iii) gearbox, (iv) lubricant, (v) protocol of the sample, (vi) traceability and (vii) comments or notes. 
Table 1. Content of the oil sample labels of eight of the main maintainers and laboratories regarding wind farm. This table includes the necessary information to identify the wind farm and the client.

\begin{tabular}{|c|c|c|c|c|c|c|c|c|}
\hline Topic & 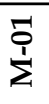 & $\begin{array}{l}\text { So } \\
\text { ì }\end{array}$ & 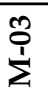 & $\begin{array}{l}\underbrace{+} \\
\sum^{1}\end{array}$ & 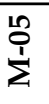 & 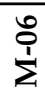 & $\begin{array}{l}\hat{0} \\
\stackrel{1}{1}\end{array}$ & 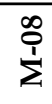 \\
\hline Name & & & & $\sqrt{ }$ & & $\sqrt{ }$ & & \\
\hline Location & $\sqrt{ }$ & & & $\sqrt{ }$ & & & & \\
\hline Country & $\sqrt{ }$ & & & $\sqrt{ }$ & & & & \\
\hline Offshore & & & & $\sqrt{ }$ & & & & \\
\hline Client & $\sqrt{ }$ & & & & & & & $\sqrt{ }$ \\
\hline
\end{tabular}

In this case, most of the information is formal data used to recognize and classify the sample. Most of the parties ignore this information and directly reference the sample with the turbine (Table 2). In the case of the offshore file, even though only one company requests it, it is important to detect if the turbine is installed at sea (offshore), due to the increment of the costs in the corrective actions, especially in the substitutions of the component. If the laboratory is familiar with this situation, they can be stricter with possible follow-up actions.

Table 2. Content of the oil sample labels of eight of the main maintainers and laboratories, including the relevant technical information of the wind turbine.

\begin{tabular}{|c|c|c|c|c|c|c|c|c|}
\hline Topic & $\sum_{\substack{1 \\
\Sigma}}^{\sigma}$ & 崩 & 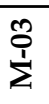 & 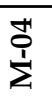 & 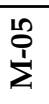 & 竞 & 竞 & $\sum_{\substack{\infty \\
1}}^{\infty}$ \\
\hline Brand (platform) & & $\sqrt{ }$ & $\sqrt{ }$ & $\sqrt{ }$ & $\sqrt{ }$ & & $\sqrt{ }$ & $\sqrt{ }$ \\
\hline Model & & $\sqrt{ }$ & & $\sqrt{ }$ & $\sqrt{ }$ & & & $\sqrt{ }$ \\
\hline Serial number & & $\sqrt{ }$ & $\sqrt{ }$ & $\sqrt{ }$ & $\sqrt{ }$ & & $\sqrt{ }$ & $\sqrt{ }$ \\
\hline Reference identification & & $\sqrt{ }$ & $\sqrt{ }$ & $\sqrt{ }$ & $\sqrt{ }$ & & & \\
\hline Operation hours & & & $\sqrt{ }$ & & & & & \\
\hline Production & & & $\sqrt{ }$ & & & & & \\
\hline Work instruction number & $\sqrt{ }$ & & & & & & & \\
\hline
\end{tabular}

On this occasion there is a part of the information related to the turbine formal data and internal registers of the wind turbine that is mainly requested. The operation hours are important in the case of substitution of the wind turbine, which is not common, but possible.

Depending on the internal organization, it is important to include the work instruction to link this internal register with the sample taken. Just one in eight cases is included.

Table 3. Content of the oil sample labels of eight of the main maintainers and laboratories, including the relevant technical information of the gearbox.

\begin{tabular}{|c|c|c|c|c|c|c|c|c|}
\hline Topic & $\begin{array}{l}\overline{1} \\
\sum_{2}^{1}\end{array}$ & 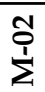 & $\begin{array}{l}0 \\
\sum_{1}^{1}\end{array}$ & 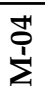 & 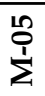 & 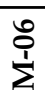 & 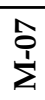 & 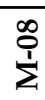 \\
\hline Brand & $\sqrt{ }$ & $\sqrt{ }$ & $\sqrt{ }$ & $\sqrt{ }$ & $\sqrt{ }$ & & $\sqrt{ }$ & \\
\hline Model & & $\sqrt{ }$ & $\sqrt{ }$ & $\sqrt{ }$ & $\sqrt{ }$ & & & \\
\hline Serial number & $\sqrt{ }$ & $\sqrt{ }$ & $\sqrt{ }$ & & $\sqrt{ }$ & & $\sqrt{ }$ & $\sqrt{ }$ \\
\hline Capacity (litres) & & & $\sqrt{ }$ & $\sqrt{ }$ & $\sqrt{ }$ & & & $\sqrt{ }$ \\
\hline Operation hours & $\sqrt{ }$ & & & $\sqrt{ }$ & $\sqrt{ }$ & $\sqrt{ }$ & $\sqrt{ }$ & $\sqrt{ }$ \\
\hline
\end{tabular}

This is the topic where there is greatest uniformity, due to this information being key to identifying the component of which the study is going to be done. The capacity of oil is 
relevant to estimate how the external contamination can alter the results, thus, facing the same quantity of contamination, the lower total quantity of oil in the gearbox, the biggest effect and backwards. The most relevant information concerning the operational hours is to know if the gearbox has been substituted and the previous trends should be reset.

Table 4. Content of the oil sample labels of eight of the main maintainers and laboratories regarding lubricant. In this table it is included the identification data of the oil and some operational aspects.

\begin{tabular}{|c|c|c|c|c|c|c|c|c|}
\hline Topic & $\sum_{\substack{1 \\
\Sigma}}^{0}$ & 章 & 卓 & 草 & $\sum_{\substack{1 \\
0}}^{20}$ & $\sum_{\substack{1 \\
\Sigma}}^{1}$ & 全 & 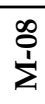 \\
\hline Brand & $\sqrt{ }$ & $\sqrt{ }$ & $\sqrt{ }$ & $\sqrt{ }$ & $\sqrt{ }$ & $\sqrt{ }$ & $\sqrt{ }$ & $\sqrt{ }$ \\
\hline $\begin{array}{l}\text { Lubricant hours (date } \\
\text { of the last oil change) }\end{array}$ & $\sqrt{ }$ & & & $\sqrt{ }$ & $\sqrt{ }$ & $\sqrt{ }$ & $\sqrt{ }$ & $\sqrt{ }$ \\
\hline $\begin{array}{l}\text { First analysis after oil } \\
\text { substitution (or new) }\end{array}$ & & & & $\sqrt{ }$ & & & & $\sqrt{ }$ \\
\hline Top up (litres) & & & $\sqrt{ }$ & $\sqrt{ }$ & $\sqrt{ }$ & & $\sqrt{ }$ & $\sqrt{ }$ \\
\hline $\begin{array}{l}\text { Oil filter substitution } \\
\text { (before the sample) }\end{array}$ & & & $\sqrt{ }$ & & $\sqrt{ }$ & & $\sqrt{ }$ & $\sqrt{ }$ \\
\hline
\end{tabular}

The information included here also gathers an important consensus in some cases. However, information such as oil top up, oil filter substitution or notice of the lubricant change cannot be considered as standard information to include in the records, despite its importance.

Table 5. Content of the oil sample labels of eight of the main maintainers and laboratories regarding protocol of the sample, that is, the position of the sample taken.

\begin{tabular}{|c|c|c|c|c|c|c|c|c|}
\hline Topic & 京 & 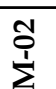 & $\begin{array}{l}0 \\
\stackrel{1}{1}\end{array}$ & $\stackrel{D}{i}_{\substack{1\\
}}$ & $\begin{array}{l}L_{0}^{2} \\
\stackrel{1}{1}\end{array}$ & 章 & 㑒 & $\begin{array}{l}\infty \\
\sum_{1}^{0}\end{array}$ \\
\hline Pro & & & & & & & & \\
\hline
\end{tabular}

Only one in eight cases registers this information. As it was demonstrated in [14], the different position of the sample taken can alter the results and therefore the conclusions.

Table 6. Content of the oil sample labels of eight of the main maintainers and laboratories regarding traceability, with the different options to check the previous sample information.

\begin{tabular}{|c|c|c|c|c|c|c|c|c|}
\hline Topic & $\sum_{\substack{1 \\
\Sigma}}^{0}$ & $\begin{array}{l}\text { Oे } \\
\stackrel{1}{\Sigma}\end{array}$ & $\stackrel{0}{1}_{\substack{1 \\
\Sigma}}$ & 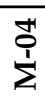 & $\begin{array}{l}\stackrel{n}{0} \\
\sum^{1}\end{array}$ & 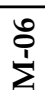 & 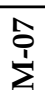 & $\begin{array}{l}\infty \\
\stackrel{\infty}{1}\end{array}$ \\
\hline Sample date & $\sqrt{ }$ & & & $\sqrt{ }$ & & $\sqrt{ }$ & $\sqrt{ }$ & $\sqrt{ }$ \\
\hline Reference of the last sample & & & $\sqrt{ }$ & $\sqrt{ }$ & & $\sqrt{ }$ & & $\sqrt{ }$ \\
\hline App (Application) & & & & $\sqrt{ }$ & & & $\sqrt{ }$ & $\sqrt{ }$ \\
\hline Barcode/QR code (Quick Response code) & & & & $\sqrt{ }$ & & $\sqrt{ }$ & $\sqrt{ }$ & $\sqrt{ }$ \\
\hline
\end{tabular}

The evolution of traceability has improved in recent years, becoming more and more relevant. New technologies in general, such as the use of smart phones, ad-hoc applications or products like QR codes, have supported this evolution. However, not in all cases is there good traceability of the analytics at different times, making it difficult to analyse the trends of the different parameters. 
Table 7. Content of the oil sample labels of eight of the main maintainers and laboratories regarding other comments or notes to add complementary information.

\begin{tabular}{|c|c|c|c|c|c|c|c|c|}
\hline Topic & 宰 & 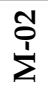 & $\stackrel{\rho}{1}_{\sum}^{1}$ & $\begin{array}{l}\stackrel{+}{1} \\
\sum\end{array}$ & $\begin{array}{l}\text { L0 } \\
\text { 1 } \\
\sum^{1}\end{array}$ & $\begin{array}{l}0 \\
\stackrel{1}{1}\end{array}$ & 号 & 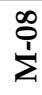 \\
\hline Notes/Comments & $\sqrt{ }$ & $\sqrt{ }$ & $\sqrt{ }$ & $\sqrt{ }$ & $\sqrt{ }$ & $\sqrt{ }$ & & \\
\hline Contact & & & & & & & & \\
\hline
\end{tabular}

Finally, in most cases, there is an option to note additional comments not included in the rest of the document.

In these seven tables it can be observed that, despite some common points existing, there is no standardization in any area and there is a significant lack of standard information in many cases. Additionally, the information does not include aspects related to the operational actions that can alter the results and recommendations. There are even some cases where some relevant information can be obtained for comparison with previous samples, but important aspects are not highlighted and can go undetected.

Considering this situation of lack of important information in many cases, the answers and conclusions can be affected, causing answers: (i) with various options, (ii) that are erroneous or (iii) at worst with unidentified issues. Therefore, the specificity in the recommendations can be altered in a similar manner. On many occasions the conclusions are focused on the direct effect on the oil, whether in additives, wear elements or others, but not so much on the origin of that effect, on what has caused it or the recommendations. As examples of type of standard answers, the following can be differenced:

- Effect on the oil:

- Silica is significantly high.

- High number of ferromagnetic particles.

- Slightly high copper content [28].

- Possible causes:

- Wear on bearings, bronze rings or pipes [29].

- Water absorption during oil storage or internal contamination.

- Mix of lubricants or external contamination.

- Pump failures or corrosion issues [30].

- Wear particles, clogging of the filtration system or external contamination [31].

- Recommendations:

- Revise the system.

- Check the reference of the oil.

- Monitor evolution.

\section{Different Situations That Affect the Results of the Analysis. Executed Gearbox Oil Operation Tests in Wind Turbines. Prognosis of Gearbox}

Once the information exchanged between different companies/laboratories has been analysed, this section details different situations that may affect the results and how this knowledge could be used to predict some events in advance, completing the necessary study to propose a template that provides detailed information to laboratories to improve the conclusions, recommendations and action plans.

This work considers two different tests that have been carried out in a total of 10 wind turbines located on two independent wind farms, complementing the five tests in a total of 30 wind turbines on five wind farms carried out in [14]. If previously actions that are performed in the O\&M such as leakage and oil filling; brand (and features) oil replacement; installation of portable or online filter; high temperature of oil; and replacement of thermostatic valves or position where the sample has been taken were explored; now others such as air filter substitution are also analysed. Additionally, the analysis of the general results and trends in cases that have ended up in damages, has been carried out to find out the 
advanced knowledge of an incident. A detailed analysis of the above actions, dedicating a section to each, is provided next.

\subsection{Air Filter Substitution}

The presence of water in the oil is another of the causes of its degradation. Although the degradation effects were more aggressive a decade ago, the chemistry of the oil has improved a lot and today's gearbox oils can hold a lot of water, since its saturation point is very high. However, the presence of water causes corrosion in the different components, and a reduction in the useful life of the oil, the bearings and other components of the gearbox. The following graph (Figure 1) shows that the drier (free of water) it is, the longer the bearing will last [32]:

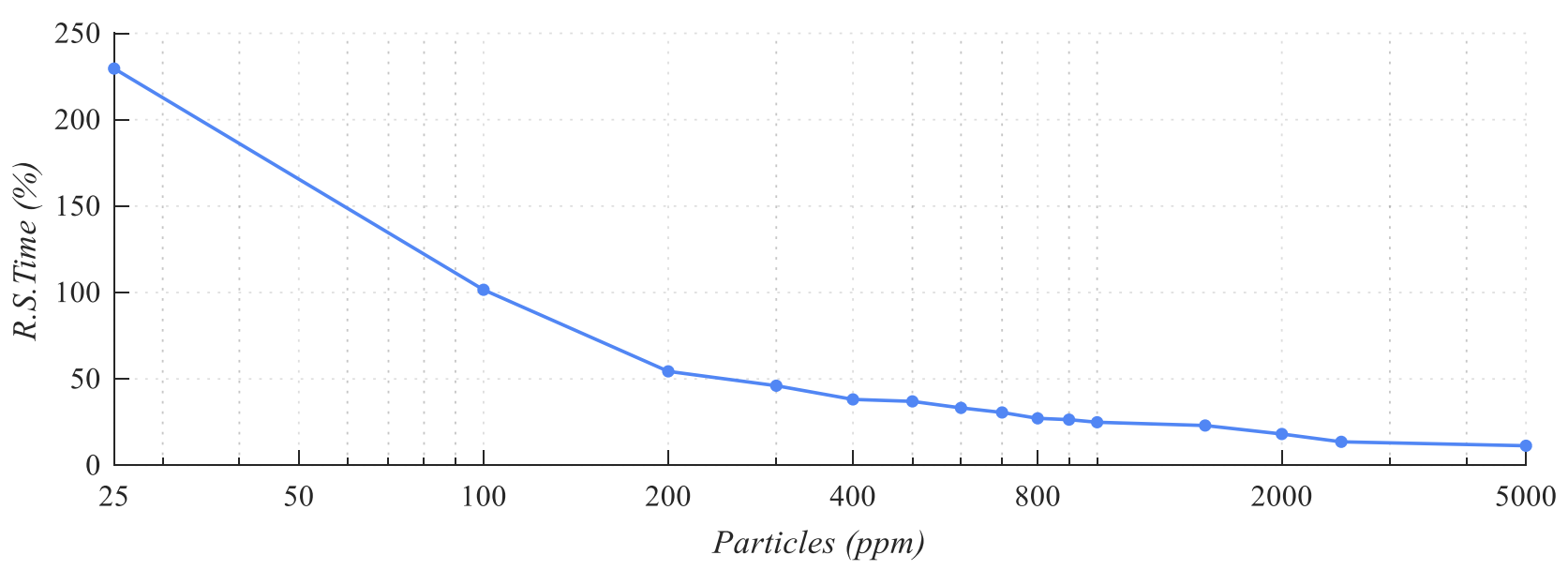

Figure 1. Relationship between water and bearing life. Based on $100 \%$ storage with $0.01 \% / 100$ ppm water in the oil [26]. can be:

The main causes of the increase in the percentage of water in the analysis results

(i) Water condensation due to low temperature operation (possible defect in the gearbox heaters) or prolonged shutdown periods. In this case water is usually found but in concentrations below $300 \mathrm{ppm}$. It is very rare for condensation to reach higher values unless the multi is open, without filter, etc.

(ii) Inclusion of water during handling by introducing new oil into the gearbox due to the humidity of some components. Sometimes mixtures with other oils are detected, including hydraulic oil (also used in other components of the wind turbine).

(iii) Possible error due to humidity contamination in the bottle where the samples are collected. This situation is quite frequent when there has been an increase in the presence of water. Sometimes the sampling protocol is not followed scrupulously and the sample is collected in water bottles that are not completely dry. They are subsequently transferred to the final bottle with that water mixed with the oil sample.

When one of these situations occurs, a specific filter can be used to decrease the presence of water in the oil and avoid its degradation. This filter is specifically designed to separate water, through a superabsorber reaction with the water present in the oil turning into a gel. These solid gel particles are collected in this filter, reducing the content of water in the oil [20].

\subsection{Prognosis of Gearbox}

Prognosis can be defined as the anticipated knowledge of an event [33]. Despite being a concept that is more typically used in other sectors such as medicine or meteorological predictions, it also has its importance and utility in engineering in general, and the oil analysis of gearboxes in particular [34]. 
This study seeks to analyse the values prior to damage, once a relevant incident that occurred such as the replacement of gears, bearings or ultimately the replacement of the gearbox. These values include previous trends to detect possible behaviour patterns that, in a high percentage will end in damage, to tackle the problem in its earliest stages.

In this case, detailed information such as the cause of the incident, the oil level, possible particles in the metal particle detectors of the gearbox, or even warnings, alarms and information from the condition monitoring system (CMS) [35] would be important for the laboratories to be able to study in depth the type of relationships between the parameters of the physical-chemical analysis of the oil and the rest of the operational information.

Nowadays, oil analytics are managed as one of the tools used to determine the status of the gearbox or at least to determine more specific measures such as endoscopies [36] or other actions. Nevertheless, to improve the reliability, scope and precision in conclusions, it is also necessary to use this information flow in reverse, in such a way that operational information helps oil analytics not only be part of the information used to make other decisions but also be part of an integral process.

\subsection{Background and Previous Studies}

Both in [14] and in this work, specific circumstances that can alter the results and conclusions of the oil analytics results have been analysed with different tests. The following compilation briefly revisits the findings in [14] and adds some further issues that were not previously studied:

\subsubsection{Oil}

- $\quad$ Brand (and features) oil replacement [14].

In an oil replacement, the substitution of the oil brand may occur in some cases. In this scenario, most of the components are similar, but the additives might change. The experimental results considered the substitution of the oil brand in 13 wind turbines at the same site and exposed to the same meteorological conditions, collecting data every six months, from 2012 to 2016 . When the oil brand is changed, remains of the old oil after cleaning and "flushing" the gearbox are not completely eliminated. Since the brand replacement in these tests implies a different chemical composition and proportions of additives (even different additives), the mixture of the remains with the new oil causes a contamination of the new results. As a consequence of this oil brand replacement, the result of the 13 tests of new oil would be flagged as a "danger" considering that there are components such as molybdenum, zinc and magnesium that widely exceed the admissible ranges for this oil brand.

\subsubsection{Sample}

- $\quad$ Position of sample taking [14].

Two samples of the same oil for the same gearbox with 320 litres of a 1.5 MW wind turbine were taken at the same time and analysed in the same world-renowned laboratory in the second quarter of 2018. The only difference is the position of the sample collection, before and after the filtering (position 1 and 2, respectively, in Figure 2).

The results show that the increase of the three types of particle sizes would be: (i) $20 \%$ in the case of particles $>4 \mu \mathrm{m}$, (ii) $33 \%$ for $>6 \mu \mathrm{m}$ and (iii) $7 \%$ in particles $>14 \mu \mathrm{m}$, concluding that the filter dirtiness has altered the values and the results can be different depending on the position sample. 


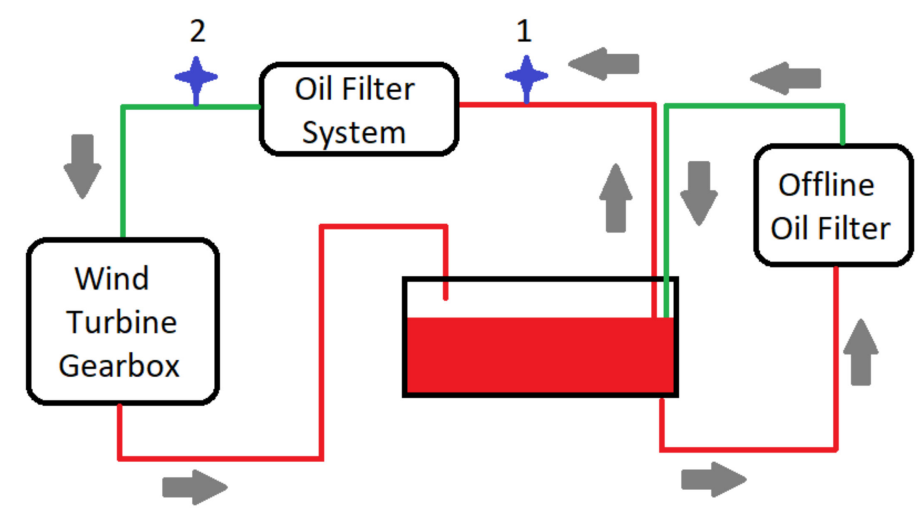

Figure 2. Gearbox oil cooling circuit. Sampling position options: option 1 when the sampling is done before the oil filter system and option 2 when the sampling is performed after the oil filter system.

\subsubsection{Incipient Damage in Gearbox/Component Replacement}

- High Temperature of Oil and Replacement of Thermostatic Valves [14].

The temperature of the gearbox oil is continuously monitored through thermovalves [24]. The internal pieces of these components are in permanent contact with the oil. When a new thermovalve is substituted, the levels of iron and copper present in their composition trigger an increase in the levels of these wear components.

The data pertaining to the period from November 2014 to December 2016 for twenty 2.5 MW wind turbines of the same technology, wind farm, site and meteorological conditions was studied to check the effect of the oil valves substitution.

After analysing the data from twenty turbines, an increase in temperatures was detected in two turbines (out of range of the average of the other 18) due to the incorrect performance of the oil valves. When the valves are substituted the oil temperature clearly goes back to close to average temperature values, but there is a relevant increase of wear elements such as zinc $(\mathrm{Zn})$ and copper $(\mathrm{Cu})$.

\subsubsection{Operation and Maintenance (O\&M)}

- Installation of Portable Off-Line Filters [14].

The oil filter is a common component in most gearboxes of multi-megawatt wind turbines, but there is a second piece of equipment called off-line filter, which is more effective and provides a higher quality filtering [22], which can be installed permanently or temporarily (Figure 3).

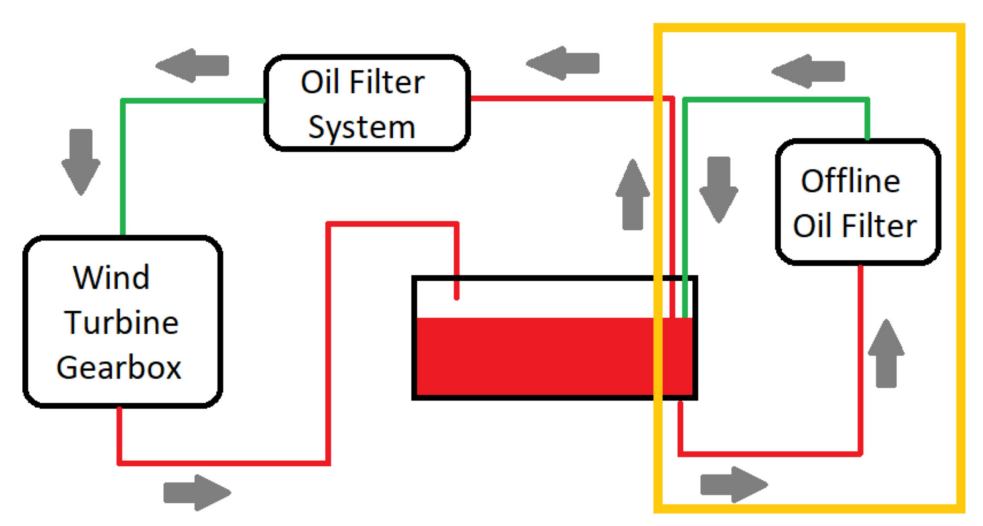

Figure 3. Gearbox oil cooling circuit. Gearbox offline oil filtration area.

The results of a test carried out in six 1.5 MW turbines of the same wind farm before and after the installation of the portable filter show that in five cases, the reduction of oil dirt and wear particles greater than $4 \mu \mathrm{m}, 6 \mu \mathrm{m}$ and $14 \mu \mathrm{m}$ is around $66 \%$, hence confirming 
the (positive) impact of the off-line filtering practice and showing how the improvement in oil condition is more evident in oils with a higher concentration of particles.

- $\quad$ Leakage and Oil Filling [14].

When a leak appears in any component of a gearbox such as joints, seals, valves or filters, there is a loss of oil volume, which results in some oil degradation [19]. This fact is usually accompanied by a filling with new oil with intact properties.

The experimental results with a gearbox of a $2.5 \mathrm{MW}$ turbine on five different occasions at a frequency of six months showed that the refill, with the intact properties of the new oil, generates a positive contamination that alters the evolution of the theoretical values in the oil analysis results and improves the general condition of the oil.

\section{Results}

The O\&M actions described in Sections 3.1 and 3.2 are analysed and discussed next in the light of extensive experimental results. Each action is individually studied in the following sections, providing real tests from 10 wind turbines that have two different technologies.

\subsection{Air Filter Substitution}

In this test, the evolution of the water presence in the oil was checked in five gearboxes of a 2.5 MW turbine on seven different occasions, labelled test 1 to test 7 , at a frequency of six months from 2015 to 2019 in a world-renowned laboratory. A continuous increment of water in the oil of the five gearboxes was taking place since 2015, with a large increase in the last months, during 2018 and 2109 (from test 5 to test 6). Immediately after test 6, special filters for water reduction were installed in the gearboxes, so they were working for six months, until the next test, number 7.

The experimental results from Figure 4 show that, after test 6, the installation of specific water reduction filters in all the gearboxes caused an important reduction in the presence of water. This drop in water values was confirmed in all the cases and, with an average reduction of $40 \%$, took them to values registered two years earlier. Here, it is confirmed that the results of the oil condition were altered (improved) due to an external action, in this case, the implementation of a special filter that reduces the water in the oil.

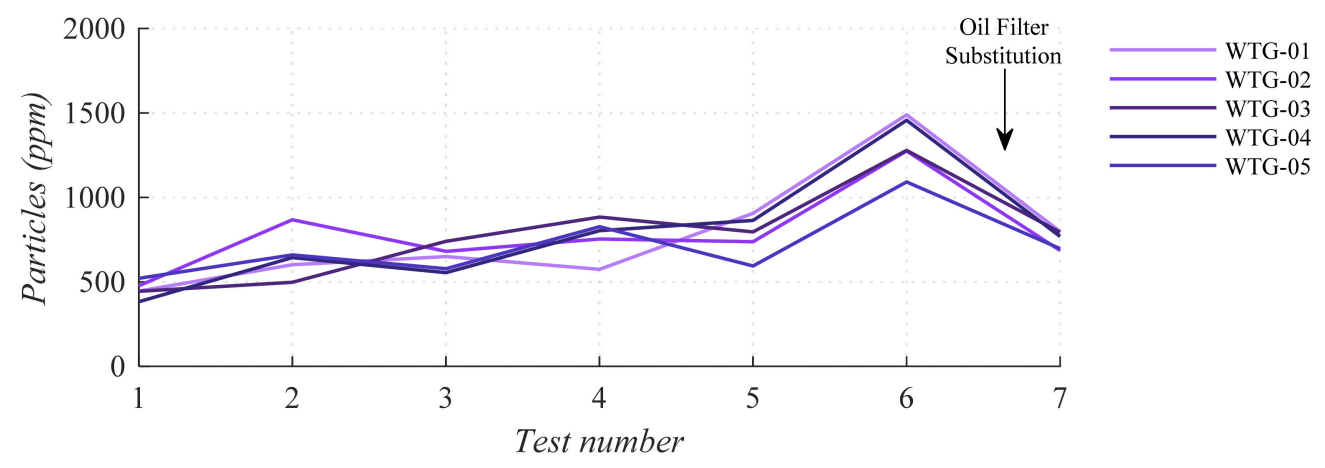

Figure 4. Water evolution in oil in five gearboxes.

\subsection{Prognosis of Gearbox Damages}

Past trends of oil results of gearboxes which have experienced degeneration, or even substitutions of these components, have been studied to analyse the evolution of the different parameters the months or years before the incident. In this case, four 2.0 MW wind turbines with the same technology in the period from 2013 to 2019 were studied.

Case 1: Figure 5 shows the evolution of the zinc $(\mathrm{Zn})$ level in the last nine tests, with a periodicity of six months between each test, from August 2013 to December 2017 in an eleven-year-old wind turbine. The increment was constant from low levels until the amount tripled, reaching the warning zone prior to dangerous values. 


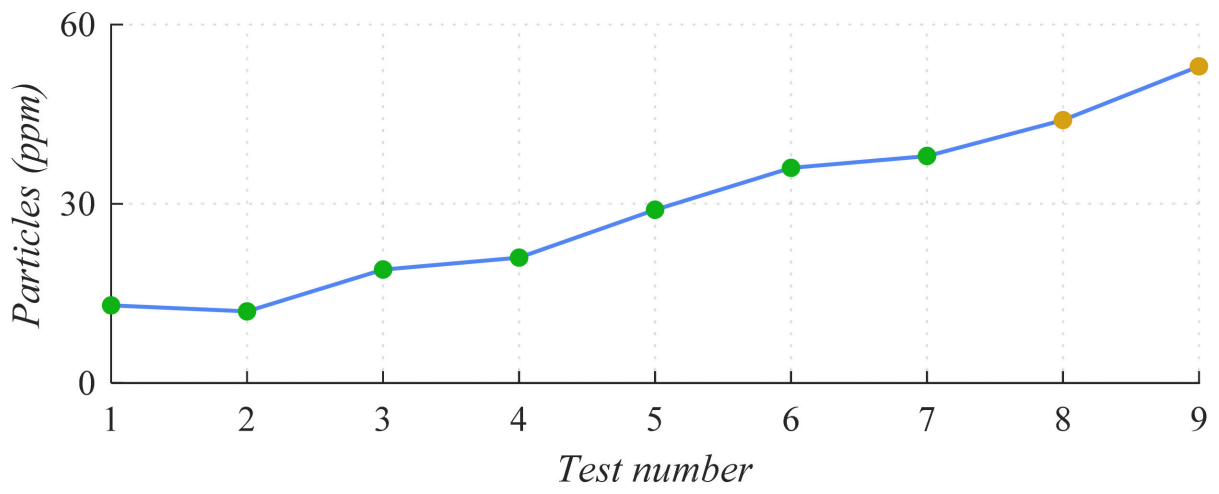

Figure 5. Evolution of Zn ppm (Zinc particles) in oil in the last nine tests.

The rest of the collected information on this gearbox registered in Table 8 does not provide any relevant suggestion of previous damages, excepting a few metal particles in the metal sensor, that is, a magnet placed inside the gearbox. This information, together with the evolution of zinc, could indicate a constant deterioration in some material with this component, such as tubes, valves or bearings, which has ultimately led to further damage.

Table 8. Compilation of operational information prior to the event in Case 1.

\begin{tabular}{|c|c|c|}
\hline \multirow{3}{*}{ Turbine detector information } & Warnings & No warnings \\
\hline & Alarms & No alarms \\
\hline & CMS & - \\
\hline \multirow{4}{*}{ Gearbox detector information } & Oil level & Ok \\
\hline & Magnet & Few particles \\
\hline & In-line filter metal particles & Few particles \\
\hline & Off-line filter metal particles & Ok \\
\hline \multirow{2}{*}{$\begin{array}{l}\text { Damages/ } \\
\text { Consequences }\end{array}$} & Damages & $\begin{array}{l}\text { Indentations and abrasive marks on gears and bearings. } \\
\text { Fractures in a bearing. }\end{array}$ \\
\hline & Consequences & $\begin{array}{l}\text { Stoppage of the turbine and substitution of the damaged } \\
\text { bearing and the next closest (for prevention). }\end{array}$ \\
\hline
\end{tabular}

Case 2: the evolution of zinc and phosphorus in Figure 6 shows a normal evolution every six months up to test 6 . From this point on a slow, but progressive reduction of the phosphorus level is identified.
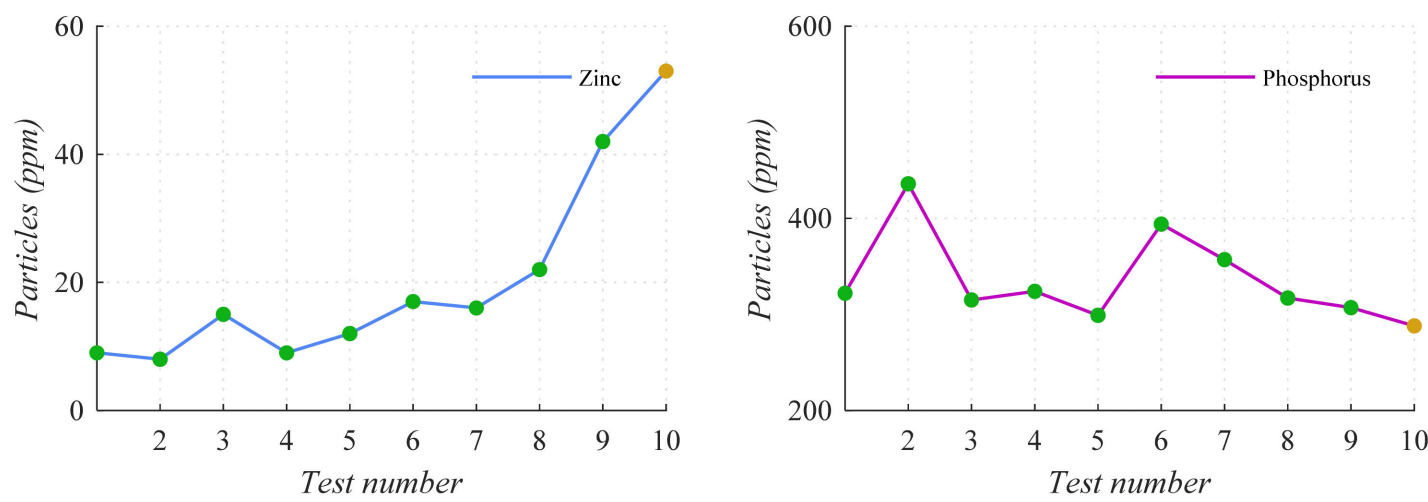

Figure 6. Evolution of Zn ppm (zinc particles) and P ppm (phosphorus particles) in oil in the last ten tests. 
In the case of zinc, an important increase in the values is reflected in the last three tests. In both cases, the values were within the normal limits, except in the previous tests to the incident, when both parameters reached a warning state. The data includes the period from June 2013 to September 2018.

Regarding the damages, Table 9 shows that a displacement of a planet gear of the gearbox was produced, which generated a detachment of metal particles and a sudden increase in temperature. Additionally, the level of oil was below the minimum level. The consequence of these serious damages was the substitution of the gearbox.

Table 9. Compilation of operational information prior to the event in Case 2.

\begin{tabular}{lll}
\hline \multirow{2}{*}{ Turbine detector information } & Warnings & No alarms \\
\cline { 2 - 3 } & Alarms & Increment of oil temperature \\
\cline { 2 - 3 } & CMS & - \\
\hline \multirow{3}{*}{ Gearbox detector information } & Oil level & Below minimum \\
\cline { 2 - 3 } & Magnet & Abundant small particles \\
\cline { 2 - 3 } & In-line filter metal particles & Abundant small particles \\
\cline { 2 - 3 } $\begin{array}{l}\text { Damages/ } \\
\text { Consequences }\end{array}$ & Off-line filter metal particles & - \\
\hline
\end{tabular}

Case 3: Figure 7 evidences that the evolution of the iron (Fe) levels has been increasing constantly every six months from the first test to the last, that is, from October 2013 to March 2019, in a thirteen-year-old wind turbine. From test 7 on the values are in a warning state and the last two tests before the stoppage show how the values continue to grow entering a danger phase.

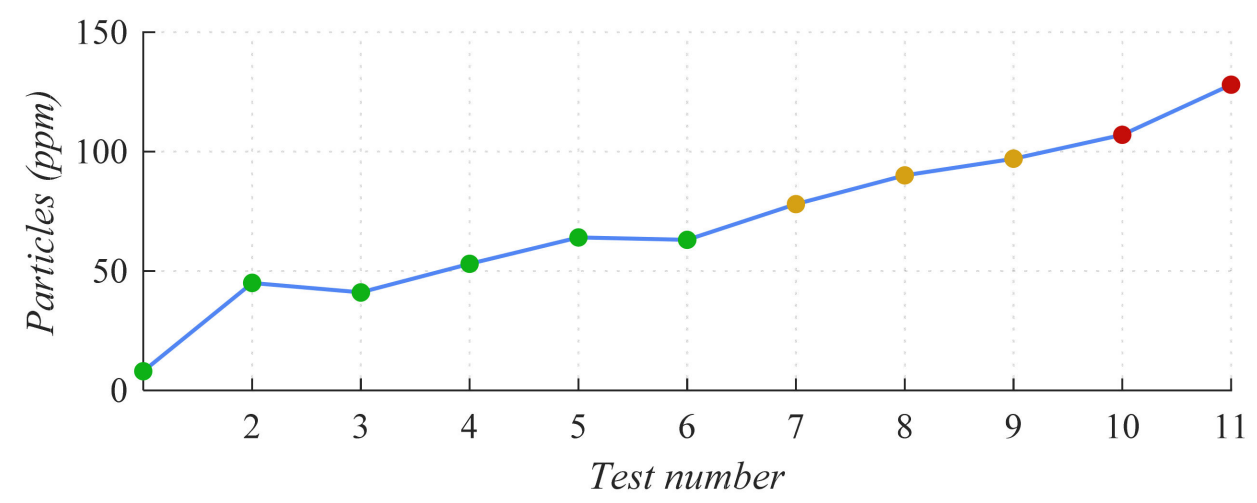

Figure 7. Evolution of Fe ppm (iron particles) in oil in the last eleven tests.

There was no additional information that revealed any damages beyond oil analysis and few small metal particles in the magnet of the gearbox, as shown in Table 10.

This case shows the importance of the oil analysis results and trends. The damaged component cannot be replaced due to the disposition in the gearbox, so the solution is to verify the status of the gearbox components using a videoscope periodically. That is, in this case a definitive solution is not possible, but the gearbox can continue operating under periodical monitoring. 
Table 10. Compilation of operational information prior to the event in Case 3.

\begin{tabular}{|c|c|c|}
\hline \multirow{3}{*}{ Turbine detector information } & Warnings & No warnings \\
\hline & Alarms & No alarms \\
\hline & CMS & - \\
\hline \multirow{4}{*}{ Gearbox detector information } & Oil level & Ok \\
\hline & Magnet & Few small particles \\
\hline & In-line filter metal particles & Ok \\
\hline & Off-line filter metal particles & - \\
\hline \multirow{2}{*}{$\begin{array}{l}\text { Damages/ } \\
\text { Consequences }\end{array}$} & Damages & $\begin{array}{l}\text { Macropitting, indentations and marks [29] in a planet } \\
\text { carrier bearing [30] }\end{array}$ \\
\hline & Consequences & $\begin{array}{l}\text { Check evolution every three months. Possible future } \\
\text { substitution }\end{array}$ \\
\hline
\end{tabular}

Case 4: the evolution of phosphorus $(\mathrm{P})$ in the oil represented in Figure 8 has suffered a relevant decrease between tests 5 and 6 , going from normal levels to warning levels. The analysis includes semiannual tests from December 2013 to March 2017.

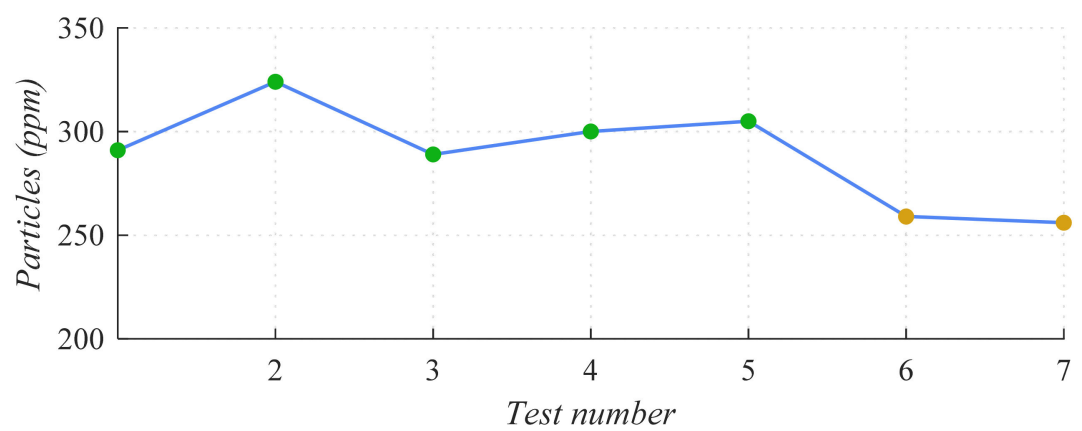

Figure 8. Evolution of P ppm (phosphorus particles) in oil in the last seven tests.

The information collected in Table 11 shows a clear case of catastrophic damage, without any relevant warnings in the different detectors of the turbine in general and the gearbox in particular. In this situation the gearbox must remain stopped until it can be replaced.

Table 11. Compilation of operational information prior to the event in Case 4.

\begin{tabular}{lll}
\hline \multirow{2}{*}{ Turbine detector information } & Warnings & No warnings \\
\cline { 2 - 3 } & Alarms & No alarms \\
\cline { 2 - 3 } & CMS & Warning \\
\hline \multirow{3}{*}{ Gearbox detector information } & Oil level & Above maximum \\
\cline { 2 - 3 } & Magnet & Few particles \\
\cline { 2 - 3 } & In-line filter metal particles & Few particles \\
\cline { 2 - 3 } Damages/ & Off-line filter metal particles & Few particles \\
Consequences & Damages & Multiple broken teeth \\
\cline { 2 - 3 } & Consequences & Substitution of the gearbox \\
\hline
\end{tabular}




\section{Sample Template Proposal}

Considering the state of art developed in Section 2, the different situations that affect the results (Sections 3 and 4) and the importance of the prognosis (Sections 3 and 4), a new global template is proposed below. The objectives of publishing this template are: (i) to be an option that can be used on any wind farm around the world, (ii) to minimize the time taken to fill out the form, (iii) to contribute to standardizing the information handled by all parties and (iv) to provide detailed information to the laboratories to improve the conclusions, recommendations and action plans.

This template has been designed with the objectives of reduction of completion times and without non-relevant information. The fulfilment of this template should be executed not only by the technicians, but also with managers or technical officers, since there are historical data and reference numbers to be located.

The method for attaching the information can be: (i) physical (on paper), including a sticker with the QR code [37] to stick on the bottles or (ii) digital, including all the information in an application (app), also making use of the $\mathrm{QR}$ code sticker.

Lastly, contact with the laboratory would be available to have support in case of doubts.

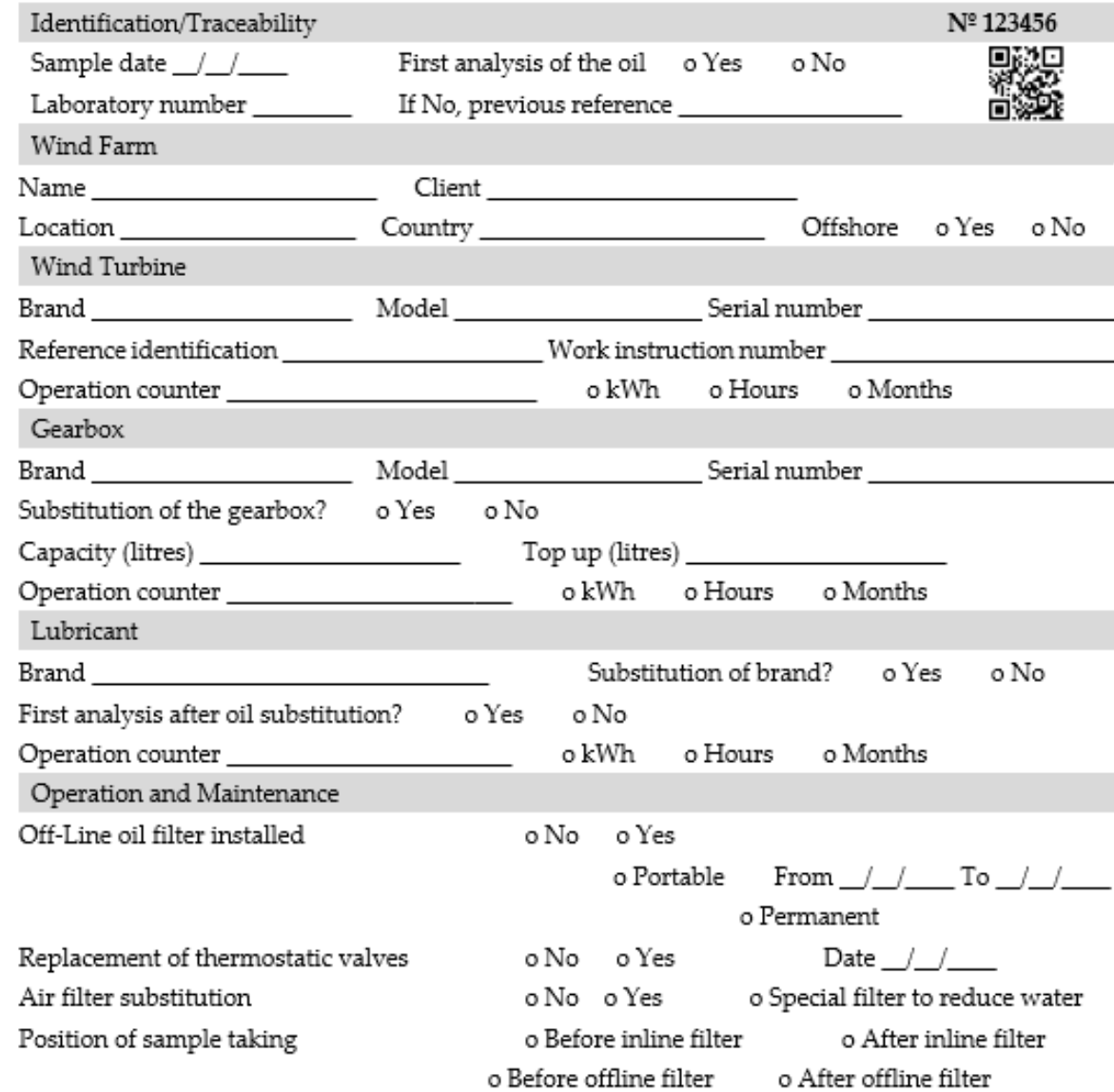

\begin{tabular}{|c|c|}
\hline & Substitution of gearbox or any internal component (bearings, gears, shafts...) \\
\hline & Warnings \\
\hline Iurbine detectors & Alarms \\
\hline information & $\mathrm{CMS}$ \\
\hline & Oil level \\
\hline Gearbox detectors & Magnet \\
\hline information & In-line filter metal particles \\
\hline & Off-line filter metal particles \\
\hline$\overline{\text { Damages/Consequ }}$ & ¿Damages \\
\hline ences & Consequences \\
\hline & Comments \\
\hline
\end{tabular}


The justification for the content of the template is explained below section by section:

(1) Identification/Traceability. In this case the identification of the sample and the assurance of the correct order of historical trends is key for a long-term analysis. As explained in Section 2, Table 6, the use of smart phones and ad-hoc applications or products like $\mathrm{QR}$ codes, can provide comfort and reliability when managing information.

(2) Wind Farm. As explained in Section 2, Table 1, most of the parties ignore this information. This template includes all the information related with the wind farm and the reference for offshore wind farms, in which case the actions and recommendations could be different.

(3) Wind Turbine. In this item, all the data registered in any case in Section 2, Table 2, are included. Nevertheless, in this case it is included an operation counter with three different options: $\mathrm{kWh}$, hours and months.

(4) Gearbox. The substitution of the gearbox has been highlighted in this template due to the relevance of this situation, even though this information could be detected with the operation counter. The possible top up has been included in this chapter with the capacity of the gearbox in order to consider the proportion of new oil and the effects on the results. The consequences of the top up are summarized in Section 3.1 Background and previous studies and demonstrated in [14].

(5) Lubricant. The change of brand has a specific and direct question to ensure that this situation is considered in the analysis. As it was demonstrated in [14] and compiled in Section 3.1, Background and previous studies, it may generate relevant consequences on the results and action plans. There is also a specific question that focuses on the first analysis after substitution, that justify the different results with the past trends. This question is different and complementary to the information included in chapter 1. Identification/Traceability, where the question is referred to the first register of the oil in the gearbox and there is not any historical information.

(6) Operation and Maintenance. Because of the analysis and tests executed and explained in [14], Section 3. Different situations that affect the results of the analysis. Executed gearbox oil operation tests in wind turbines. Prognosis of gearbox and Section 4 . Results, this chapter includes specific and novel questions regarding different situations that occur in the operation and maintenance of a wind turbine. The correct answer to these questions, including periods or dates, are critical to achieve reliable results and conclusions in these cases.

(7) Substitution of gearbox or any internal component (bearings, gears, shafts ... ). In this case, when a substitution of an internal component of the gearbox is executed, it is relevant to collect all the available registers from different sources of information provided by the wind turbine. In Section 3.3 Prognosis of Gearbox it is explained the value of this detailed information for the laboratories. In Section 4.2. Prognosis of Gearbox Damages four cases have been analysed showing the evolution of different parameters during the previous years to the incident and its consequences.

(8) Comments. If any relevant information is not included in the previous questions, it can be highlight in this section. The contact with the laboratory should be included to have access to solve questions or doubts.

\section{Conclusions and Future Outlook}

After analysing different situations and events relatively habitual in the operation and maintenance of the gearbox of a wind turbine, this study has demonstrated that the oil analysis results can be altered. As important as detecting these situations is to verify how the data collected by the different operators and transferred to the laboratories does not include this information in most cases.

All these events studied in this article and in [14] describe different situations that can alter the results and confirm the approaches: (i) air filter substitution, (ii) brand (and features) oil replacement, (iii) high temperature of oil and replacement of thermostatic valves, $(i v)$ installation of portable off-line filters, $(v)$ leakage and oil filling or (vi) position of 
sample collection. Additionally, the study of the anticipated knowledge of some incidents confirms the importance of collecting and analysing the information of aspects related with the past operation of the gearbox and how future damages can be anticipated in some cases.

The consequences of this situation can be, on the one hand the execution of new unnecessary tasks and costs such as: (i) oil refills, (ii) offline filtering, (iii) new oil samplings, $(i v)$ videoscopes or $(v)$ vibration analysis, including technicians' extra work and loss of production. On the other hand, without reliable information that warns of risk situations, no actions can be taken and the propagation of the problem cannot be stopped, leading to need for replacement of components, even complete gearboxes, with production loss and associated crane costs.

The proposal included in this paper seeks to incorporate new information in a routine and standardized way to generate a new climate of collaboration between the parties. It is necessary to understand that information must flow in both directions to provide each other with feedback and increasingly count on more reliable conclusions. Using this template would be a "win-win" for both parties. Therefore, it is necessary to impregnate this culture of collaboration throughout the value chain, both on the maintainer side, with the process of taking samples and sending information to the laboratory, and the laboratory side, to deepen the knowledge of the situations that may have affected the results, as well as to provide more accurate conclusions and recommendations.

The maintainer must bear in mind that filling in the oil information is not a mere procedure, rather something that will take more time, but that will record tremendously valuable information. Additionally, it should be taken into consideration that, without the data, they would be able to improve the systems in this sector but would never have the necessary input data. When taking an oil sample, the canister with the amount of oil to be analysed should be considered as important as the information attached to that canister. It must be considered that information that has been generated for six months (or the time that is determined) is as important at a particular level in the short term, as at a global level in the medium-long term.

The proposed template has been designed after an in-depth study from extensive experimental results with the aim of creating a practical tool that can be used imminently in any technology worldwide. From there, laboratories will be able to receive this information and standardize, analyse, apply algorithms and even artificial intelligence to derive patterns of behaviour with the information from the millions of annual samples they analyse. This will help laboratories to predict future results based on the actions carried out on the gearbox and deal with values altered by external agents as a result of any of these specific actions. Even with a few improvements applied, the global impact could be enormous in terms of the benefits and ultimately it would be an advance in the evolution of the operation and maintenance of wind farms that would become a permanent fixture.

In this way, the objective of future research is to better understand these patterns of behaviour taking into account all the new available information that the laboratories will have obtained using statistical methods.

Author Contributions: Data curation, J.R.d.Á.S.; Investigation, J.R.d.Á.S.; Methodology, M.J.D.M., J.A. and F.J.M.G.; Supervision, M.J.D.M. and F.J.M.G.; Writing—original draft, J.R.d.Á.S.; Writingreview \& editing, M.J.D.M. and F.J.M.G. All authors have read and agreed to the published version of the manuscript.

Funding: Please add: This research received no external funding.

Institutional Review Board Statement: Not applicable.

Informed Consent Statement: Not applicable.

Conflicts of Interest: The authors declare no conflict of interest. 


\section{References}

1. Ohlenforst, K.; Sawyer, S. Dutton. Global Wind Report 2018; Technical Support; Global Wind Energy Council: Brussels, Belgium, 2019.

2. Yildirim, M.; Gebraeel, N.Z.; Sun, X.A. Integrated predictive analytics and optimization for opportunistic maintenance and operations in wind farms. IEEE Trans. Power Syst. 2017, 32, 4319-4328. [CrossRef]

3. Shafiee, M.; Sørensen, J.D. Maintenance optimization and inspection planning of wind energy assets: Models, methods and strategies. Reliab. Eng. Syst. Safety 2019, 192, 105993. [CrossRef]

4. Jiménez, A.E.; Bermúdez, M.D.; Iglesias, P.; Carrión, F.J.; Martínez-Nicolás, G. 1-N-alkyl-3-methylimidazolium ionic liquids as neat lubricants and lubricant additives in steel-aluminium contacts. Wear 2006, 260, 766-782. [CrossRef]

5. Bezzaoucha, F.S.; Sahnoun, M.H.; Benslimane, S.M. Failure causes based wind turbine components classification and failure propagation: For proactive maintenance implementatio. In Proceedings of the 2018 International Conference on Wind Energy and Applications in Algeria (ICWEAA), Algiers, Algeria, 6-7 November 2018; pp. 1-6.

6. Sinha, Y.; Steel, J.A.; Andrawus, J.A.; Gibson, K. Significance of Effective Lubrication in Mitigating System Failures-A Wind Turbine Gearbox Case Study. Wind Eng. 2014, 38, 441-449. [CrossRef]

7. Sheng, S.; Mcdade, M.; Errichello, R. Wind Turbine Gearbox Failure Modes: A Brief; National Renewable Energy Laboratory: Golden, CO, USA, 2011.

8. Junior, V.J.; Zhou, J.; Roshanmanesh, S.; Hayati, F.; Hajiabady, S.; Li, X.Y.; Dong, H.; Papaelias, M. Evaluation of damage mechanics of industrial wind turbine gearboxes. Insight-Non-Destr. Test. Cond. Monit. 2017, 59, 410-414. [CrossRef]

9. Roggenburg, M.; Esquivel-Puentes, H.A.; Vacca, A.; Evans, H.B.; Garcia-Bravo, J.M.; Warsinger, D.M.; Ivantysynova, M.; Castillo, L. Techno-economic analysis of a hydraulic transmission for floating offshore wind turbines. Renew. Energy 2020, 153, 1194-1204. [CrossRef]

10. Enevoldsen, P.; Xydis, G. Examining the trends of 35 years growth of key wind turbine components. Energy Sustain. Dev. 2019, 50, 18-26. [CrossRef]

11. Churchfield, M.J.; Lee, S.; Michalakes, J.; Moriarty, P.J. A numerical study of the effects of atmospheric and wake turbulence on wind turbine dynamics. J. Turbul. 2012, 13, N14. [CrossRef]

12. Carroll, J.; McDonald, A.; McMillan, D. Failure rate, repair time and unscheduled O\&M cost analysis of offshore wind turbines. Wind Energy 2016, 19, 1107-1119.

13. Nachimuthu, S.; Zuo, M.J.; Ding, Y. A decision-making model for corrective maintenance of offshore wind turbines considering uncertainties. Energies 2019, 12, 1408. [CrossRef]

14. del Álamo, J.R.; Duran, M.J.; Muñoz, F.J. Analysis of the Gearbox Oil Maintenance Procedures in Wind Energy. Energies 2020, 13, 3414. [CrossRef]

15. Ackermann, T.; Söder, L. Wind energy technology and current status: A review. Renew. Sustain. Energy Rev. 2000, 4, 315-374. [CrossRef]

16. Ragheb, A.; Ragheb, M. Wind turbine gearbox technologies. In Proceedings of the 2010 1st International Nuclear \& Renewable Energy Conference (INREC), Amman, Jordan, 21-24 March 2010; pp. 1-8.

17. Pozo, F.; Vidal, Y.; Salgado, Ó. Wind turbine condition monitoring strategy through multiway PCA and multivariate inference. Energies 2018, 11, 749. [CrossRef]

18. Nicholas, G.; Clarke, B.P.; Dwyer-Joyce, R.S. Detection of Lubrication State in a Field Operational Wind Turbine Gearbox Bearing Using Ultrasonic Reflectometry. Lubricants 2021, 9, 6. [CrossRef]

19. Pozo, F.; Vidal, Y.; Serrahima, J.M. On real-time fault detection in wind turbines: Sensor selection algorithm and detection time reduction analysis. Energies 2016, 9, 520. [CrossRef]

20. Pozo, F.; Vidal, Y. Wind turbine fault detection through principal component analysis and statistical hypothesis testing. Energies 2016, 9, 3. [CrossRef]

21. Tang, M.; Zhao, Q.; Ding, S.X.; Wu, H.; Li, L.; Long, W.; Huang, B. An improved lightGBM algorithm for online fault detection of wind turbine gearboxes. Energies 2020, 13, 807. [CrossRef]

22. Velandia-Cardenas, C.; Vidal, Y.; Pozo, F. Wind Turbine Fault Detection Using Highly Imbalanced Real SCADA Data. Energies 2021, 14, 1728. [CrossRef]

23. Dempsey, P.J.; Lewicki, D.G.; Decker, H.J. Investigation of Gear and Bearing Fatigue Damage Using Debris Particle Distributions; National Aeronautics and Space Administration Cleveland Oh Glenn Research Center: Belvoir, VA, USA, 2004.

24. Wind Turbine Manufactures. Online Access. The Wind Power. Wind Energy Market Intelligence. Available online: https: / / www.thewindpower.net/online_access_en.php (accessed on 8 September 2020).

25. Oil and Petroleum Testing Laboratories. Contract Laboratories by Industries and Products; Contract Laboratory: Boise, ID, USA, 2020.

26. Hydac International. Betamicron ${ }^{\circledR} /$ Aquamicron ${ }^{\circledR}-$ Filter Elements; Hydac International: Sulzbach, Germany, 2019.

27. De Novaes Pires Leite, G.; Araújo, A.M.; Rosas, P.A.C. Prognostic techniques applied to maintenance of wind turbines: A concise and specific review. Renew. Sustain. Energy Rev. 2018, 81, 1917-1925. [CrossRef]

28. Adebogun, A.; Hudson, R.; Breakspear, A.; Warrens, C.; Gholinia, A.; Matthews, A.; Withers, P. Industrial gear oils: Tribological performance and subsurface changes. Tribol. Lett. 2018, 66, 65. [CrossRef]

29. Gould, B.; Demas, N.G.; Pollard, G.; Rydel, J.J.; Ingram, M.; Greco, A.C. The effect of lubricant composition on white etching crack failures. Tribol. Lett. 2019, 67, 7. [CrossRef] 
30. Lisiecki, A. Tribology and Surface Engineering; Coatins: Gliwice, Poland, 2019.

31. International Organization for Standardization. Standard, British. BS ISO 4406: 1999 Hydraulic Fluid Power-Fluids—Method for Coding the Level of Contamination by Solid Particles; International Organization for Standardization: Geneva, Switzerland, 1999.

32. Timken Bearing Co. How Dirt and Water Affect Bearing Life. Machine Design; Timken Bearing Co.: North Canton, OH, USA, 1986.

33. Zhang, X.; Kang, J.; Zhao, J.S.; Cao, D.C. Features for fault diagnosis and prognosis of gearbox. Chem. Eng. Trans. 2013, 33, $1027-1032$

34. Teng, W.; Zhang, X.; Liu, Y.; Kusiak, A.; Ma, Z. Prognosis of the remaining useful life of bearings in a wind turbine gearbox. Energies 2017, 10, 32. [CrossRef]

35. Giebhardt, J. Wind turbine condition monitoring systems and techniques. In Wind Energy Systems; Woodhead Publishing: Cambridge, UK, 2011; pp. 329-349.

36. Tchakoua, P.; Wamkeue, R.; Tameghe, T.A.; Ekemb, G. A review of concepts and methods for wind turbines condition monitoring. In Proceedings of the 2013 World Congress on Computer and Information Technology (WCCIT), Sousse, Tunisia, 22-24 June 2013; pp. 1-9.

37. Sankara, N. QR Codes and Security Solutions. Int. J. Comput. Sci. Telecommun. 2012, 3, 7. 